\title{
Climate and hydrological variability: the catchment filtering role
}

\author{
I. Andrés-Doménech ${ }^{1}$, R. García-Bartual ${ }^{1}$, A. Montanari $^{2}$, and J. B. Marco ${ }^{1}$ \\ ${ }^{1}$ Instituto Universitario de Investigación de Ingeniería del Agua y Medio Ambiente, Universitat Politècnica de València, \\ Camino de Vera s/n, 46022 Valencia, Spain \\ ${ }^{2}$ Facoltà di Ingegneria, Università di Bologna, Via del Risorgimento 2, 40136 Bologna, Italy
}

Correspondence to: I. Andrés-Doménech (igando@hma.upv.es)

Received: 3 September 2014 - Published in Hydrol. Earth Syst. Sci. Discuss.: 17 September 2014

Revised: 6 December 2014 - Accepted: 25 December 2014 - Published: 21 January 2015

\begin{abstract}
Measuring the impact of climate change on flood frequency is a complex and controversial task. Identifying hydrological changes is difficult given the factors, other than climate variability, which lead to significant variations in runoff series. The catchment filtering role is often overlooked and thus may hinder the correct identification of climate variability signatures on hydrological processes. Does climate variability necessarily imply hydrological variability? This research aims to analytically derive the flood frequency distribution based on realistic hypotheses about the rainfall process and the rainfall-runoff transformation. The annual maximum peak flow probability distribution is analytically derived to quantify the filtering effect of the rainfall-runoff process on climate change. A sensitivity analysis is performed according to typical semi-arid Mediterranean climatic and hydrological conditions, assuming a simple but common scheme for the rainfall-runoff transformation in small-size ungauged catchments, i.e. the CN-SCS model. Variability in annual maximum peak flows and its statistical significance are analysed when changes in the climatic input are introduced. Results show that depending on changes in the annual number of rainfall events, the catchment filtering role is particularly significant, especially when the event rainfall volume distribution is not strongly skewed. Results largely depend on the return period: for large return periods, peak flow variability is significantly affected by the climatic input, while for lower return periods, infiltration processes smooth out the impact of climate change.
\end{abstract}

\section{Introduction}

Many of the concerns about climate change are related to its effects on the hydrological cycle (Kundzewicz et al., 2007, 2008; Koutsoyiannis et al., 2009; Bloeschl and Montanari, 2010), and more specifically, its impact on freshwater availability and flood frequency (Milly et al., 2002; Kay et al., 2006; Allamano et al., 2009). However, results from recent studies about climate change impacts on flood frequency have not been conclusive (Kay et al., 2006). Indeed, detecting changes in flood frequency is not easy, because there are factors other than climate variability that may lead to significant changes - for instance, spatial variability of watershed properties or changes in the channel network geometry and land-use change (Milly et al., 2002). In particular, river bed geometry alterations, even if localized, can significantly affect flood magnitude. Therefore, to better identify climate impacts, one should focus on catchments that are in close to pristine conditions (Di Baldassarre et al., 2010).

This research addresses an issue that is often overlooked and which may hinder the proper identification of climate variability effects on hydrological processes - namely, the filtering role played by catchment. In fact, runoff can be interpreted as a smoothed convolution of past and current rainfall, where smoothing is operated over the catchment contributing area and along the concentration time. Depending on the catchment's physical characteristics and meteorological conditions, smoothing may average out changes in rainfall distribution in space and time and hence cancel out climate variability. This is a key reason why climate variability effects might not be clearly visible in the hydrology response. In other words, climate variability does not necessarily imply hydrological variability. This issue has been also investi- 
gated for an urban hydrology context. For example, AndrésDoménech et al. (2012) analysed storm tank resilience to changes in rainfall statistics, proving that the effect of climate variability on storm tank efficiency is likely to be smoothed out by the filtering effect caused by the urban catchment.

In the present study, modelling efforts are basically centred on the role of climatic variability and its effects on catchment hydrological response, with rainfall statistical properties and their future trends representing the major factors controlling flood frequency distribution. It should be noted that other factors, such as land use change, might have a more significant impact than climate change itself under certain hydrological conditions. The present research focuses on climatic impacts alone: interactions at the catchment scale between landscape characteristics (soils, vegetation and geology, for instance) and climatic properties (Troch et al., 2013), or possible climate-vegetation-soil feedbacks are not considered as they may hinder the assessment of climatic effects.

The modelling framework and simulations performed in this study focus on rainfall patterns' variability, using a suitable modelling framework to investigate the extent to which such rainfall variations can actually be buffered by a given standard hydrological catchment, with typical response parameters of a small catchment in a semi-arid Mediterranean region. Thus, heterogeneity in catchment physical properties, which has provided contrasting and sometimes contradictory results (Sangati et al., 2009), is not considered in the presented approach. Runoff statistics sensitivity to spatial heterogeneity is in principle less significant as the catchment area is smaller and therefore more homogeneous. In our case, we assume that the concentration time is short, therefore implying that the catchment area is small. Thus, the lumped modelling assumption can be considered reasonable for the purpose of the study.

To assess climatic impacts, the frequency of occurrence of peak flows is estimated by means of a derived distribution approach, which is particularly useful to obtain probability distributions of peak flows in ungauged or poorly observed basins. In such cases design floods are calculated from a hydrological model, which is driven by historical or synthetic rainfall data (Haberlandt and Radtke, 2014). The derived flood frequency analysis was also used by Gaume (2006) to investigate the asymptotic behaviour of flood peak distributions from rainfall statistical properties, highlighting the strong dependence of peak flow distribution on rainfall statistical properties, and considering a limited and reasonable hypothesis on the rainfall-runoff transformation.

Accordingly, a stochastic process is used here to model rainfall and a simple deterministic lumped model is proposed to simulate the rainfall-runoff transformation. Such an analytical approach, which has a long history of application in hydrology (see, for instance, Eagleson, 1972 and Papa and Adams, 1997), presents several advantages. The most relevant is the opportunity to analytically assess the cause-effect relationships that take place in the rainfall-runoff transformation.

However, the analytical approach requires the use of models that lend themselves to analytical developments, which are obtained by using simplified representations. Therefore our analysis, being based on the use of an analytical model, cannot account for the overall complexity of catchment processes. Consequently, a simplified representation of hydrological processes is considered herein, without including detailed effects.

Under such assumptions, the aim of this research is to quantify the actual extent to which the rainfall-runoff process actually filters the impact of rainfall variability on runoff annual maximum peak flow series. The flood frequency distribution is analytically derived for a hypothetical catchment based on plausible assumptions about the rainfall process and the rainfall-runoff transformation. Having derived the peak flow probability distribution, one may quantify the smoothing brought on by the rainfall-runoff process. A hypothetical case study is developed according to climatic and hydrological conditions typical of the Valencia region (Spain), described in Sect. 2.2. As also described later, the rainfall-runoff model proposed assumes a simple but common scheme for small, fast-responding, ungauged catchments, subjected to erratic hydrological regimes (Ferrer Polo, 1993; Soulis and Valiantzas, 2012).

\section{Analytical model}

We set up an analytical model to describe the river flow regime for a hypothetical catchment, based on analytical descriptions of rainfall and rainfall-runoff transformation. Under suitable assumptions which are described below, this model allows us to derive the annual maximum flood frequency distribution, depending on climate and catchment behaviour.

The analysis presented herein is an event-based approach, where each rainfall-runoff event is treated as an independent event. In the Valencia region, as in other many semiarid locations around the Mediterranean, ephemeral rivers are closely related to small and fast-responding catchments. Such regimes, also named as "erratic regimes" according to the classification provided by Botter et al. (2013), occur when rainfall inter-arrival times are somewhat longer than the typical duration of the resulting flow pulses, as the case presented in this study. As pointed out by Andrés-Doménech et al. (2010), antecedent dry periods for the considered climate can be assumed to be exponentially distributed with a $22 \mathrm{~h}$ low bound and an 8-day expected mean value. With such a sporadic rainfall regime, antecedent moisture conditions are mainly related to the event itself and rainfall intensities during the initial stages of the storm, so that the assumption of independence for subsequent events is plausible. More- 
over, for this type of hydrological event, direct runoff is the dominant component of the hydrograph.

To carry out this analysis, we assume that the rainfall forcing in the present climate can be modelled by a stationary model. Thus, non-stationarity can be accounted for by changing the parameters of the rainfall model at a given time when climate variability is supposed to occur. Such a change in the rainfall model parameters implies a corresponding deterministic change of rainfall statistics and therefore non-stationarity (Koutsoyiannis and Montanari, 2014; Montanari and Koutsoyiannis, 2014). Non-stationarity in the river flow is assumed to occur for the presence of the above non-stationarity in rainfall and thus is quantified through the proposed approach.

\subsection{Rainfall description}

A rainfall analytical model is used to describe the occurrence of the rainfall process over time. We adopt a stochastic rectangular-pulse model that simulates rainfall dynamics by assuming that rainfall events occur as independent rectangular pulses over time. Events are assumed to occur according to a Poisson process (Madsen and Rosbjerg, 1997; Madsen et al., 1997) and thus the probability of experiencing $n$ rainfall events in the time span $[0, t]$ is given by

$P[n]=\frac{(\beta t)^{n}}{n !} e^{-\beta t}$,

where $\beta$ is the mean number of rainfall events per unit time. Event rainfall depth $(v)$ is assumed to be independent and the result of a generalized Pareto distribution (AndrésDoménech et al., 2010). This model provided a good fit for the rainfall series of Valencia (Spain), recorded with $5 \mathrm{~min}$ resolution by the Júcar River basin hydrological service (SAIH) during the period 1990-2006. Andrés-Doménech et al. (2010) also found the model to be accurate for other locations in Spain. Other authors have also reported good results in other Mediterranean locations (Tzavelas et al., 2010).

The distribution function of the generalized Pareto distribution is given by

$F_{\mathrm{V}}(v)=1-\left(1-\kappa \frac{v}{\alpha}\right)^{1 / \kappa} \quad v \geq 0$,

where $\kappa<0$ and $\alpha>0$ are the shape and scale parameters, respectively.

For the region that is considered in the study, convective storms usually occur during autumn, particularly in September and October, while frontal events mostly occur during winter and spring. Thus, maximum rainfall peaks occur systematically during autumn. The rainfall model that we use can potentially reproduce both frontal and convective events (see, for instance, Andrés-Doménech et al., 2010). Consequently, seasonality is not specifically accounted for. We assume that climatic variability may occur through an intensification of rainfall events, and we investigate the conditions under which it may imply or not an amplification of annual maximum floods - that is, to what extent the rainfall-runoff transformation may filter out or amplify the effects of climate variability.

\subsection{Rainfall-runoff description}

To conceptualize rainfall-runoff transformation, the SCSCN event-based model was adopted. This model has been widely used in Spain (Ferrer Polo, 1993) and other Mediterranean countries (Soulis and Valiantzas, 2012). In this model, runoff volume, $r(v)$, is related to event rainfall volume $v$ by the following relationship:

$\begin{cases}r(v)=0 & \text { if } v \leq I_{\mathrm{a}} \\ r(v)=\frac{\left(v-I_{\mathrm{a}}\right)^{2}}{v-I_{\mathrm{a}}+S} & \text { if } v>I_{\mathrm{a}},\end{cases}$

where $I_{\mathrm{a}}=k S$ is the initial rainfall abstraction, $S$ is the catchment storage capacity and $k$ is the initial abstraction coefficient. By assuming the dimensionless SCS unit hydrograph (SCS, 1971), each rainfall event produces a single-peak triangular hydrograph. The specific peak river flow can be expressed as

$q_{\mathrm{P}}(v)=\lambda_{\mathrm{P}} \frac{r(v)}{t_{\mathrm{C}}}$,

where $r(v)$ is the runoff event volume computed by Eq. (3), $t_{\mathrm{C}}$ is the concentration time of the catchment and $\lambda_{\mathrm{P}}$ is a dimensionless peak factor.

The original SCS model recommends a standard value $\lambda_{P}=9 / 8$, implying that $3 / 8$ of the total runoff volume occurs before the peak, being the time to peak equal to $2 t_{\mathrm{C}} / 3$ from the beginning of net rainfall. For the particular case of semiarid regions in Spain, a value $\lambda_{P}=5 / 3$ is recommended (Ferrer Polo, 1993) to take into account the faster hydrological response.

\subsection{Deriving the peak flow probability distribution}

The rainfall and rainfall-runoff analytical descriptions allow for the analytical derivation of the probability distribution function (PDF) of all events peak flow. Assuming that no runoff occurs if $v<I_{\mathrm{a}}$,

$F_{Q_{\mathrm{P}}}(0)=F_{\mathrm{V}}\left(I_{\mathrm{a}}\right)=1-\left(1-\kappa I_{\mathrm{a}} / \alpha\right)^{1 / \kappa}$,

where $Q_{\mathrm{P}}$ indicates the stochastic process whose outcome is the event peak flow $q_{\mathrm{P}}(t)$. On the other hand, when initial abstraction $I_{\mathrm{a}}$ is exceeded then $Q_{\mathrm{P}}>0$, and the related cumulative probability distribution is 


$$
\begin{aligned}
F_{Q_{\mathrm{P}}}\left(q_{\mathrm{P}}\right) & =\int_{0}^{q_{\mathrm{P}}} f_{Q_{\mathrm{P}}}\left(q_{\mathrm{P}}\right) \mathrm{d} q_{\mathrm{P}}=F_{Q_{\mathrm{P}}}(0) \\
& +\int_{I_{\mathrm{a}}}^{v} f_{\mathrm{V}}(v) \mathrm{d} v=1-(1-\kappa v t / \alpha)^{1 / \kappa} .
\end{aligned}
$$

Combining these expressions with Eqs. (3) and (4) leads to

$F_{Q_{\mathrm{P}}}\left(q_{\mathrm{P}}\right)= \begin{cases}1-\left(1-\kappa I_{\mathrm{a}} / \alpha\right)^{1 / \kappa} & q_{\mathrm{P}}=0 \\ 1-\left\{1-\frac{\kappa}{\alpha}\left[I_{\mathrm{a}}+\frac{t_{\mathrm{C}} q_{\mathrm{P}}}{2 \lambda_{\mathrm{P}}}\left(1+\sqrt{\left.\left.\left.1+\frac{4 \lambda_{\mathrm{P}} S}{t_{\mathrm{C}} \mathrm{P}}\right)\right]\right\}^{1 / \kappa}}\right.\right.\right. & q_{\mathrm{P}}>0 .\end{cases}$

As previously explained, it should be noted that these rainfall and rainfall-runoff models assume statistical independence of peak river flow over time. Therefore, the distribution function of maximum annual floods $Q_{\mathrm{Pm}}$ can be expressed as (see, for instance, Viglione and Blöschl, 2009)

$F_{Q \mathrm{Pm}}\left(q_{\mathrm{Pm}}\right)=e^{-\beta\left(1-F_{Q}\left(q_{\mathrm{P}}\right)\right)}$,

where $\beta$ is the annual number of rainfall events. In terms of return period, the $T$-year maximum peak flow can be expressed as:

$q_{\mathrm{Pm}, T}=F_{Q_{\mathrm{P}}}^{-1}\left[\frac{1}{\beta} \ln \left(1-\frac{1}{T}\right)+1\right]$.

This analysis is equivalent to an Annual Maximum Series analysis of flood flows, as the flood events are assumed to be independent (Andrés-Doménech et al., 2010).

\subsection{Confidence intervals of peak flow PDF}

Asymptotic properties of the maximum likelihood estimators (MLEs) of the generalized Pareto distribution (Eq. 2) such as consistency, normality and efficiency were obtained by Smith (1984). The MLEs $(\kappa, \alpha)$ are asymptotically normal (De Zea Bermudez and Kotz, 2010) with a variancecovariance matrix given by

$$
\left[\begin{array}{ll}
\sigma_{\kappa}^{2} & \sigma_{\kappa \alpha} \\
\sigma_{\kappa \alpha} & \sigma_{\alpha}^{2}
\end{array}\right]=\frac{1}{n}\left[\begin{array}{ll}
(1-\kappa)^{2} & \alpha(1-\kappa) \\
\alpha(1-\kappa) & 2 \alpha^{2}(1-\kappa)
\end{array}\right],
$$

where $n$ is the sampling size. Consequently, the correlation coefficient is

$\rho_{\kappa \alpha}=\frac{1}{\sqrt{2(1-\kappa)}}$.

Monte Carlo simulations are performed to generate 1000 pairs $(\kappa, \alpha)$ normally distributed according to Eq. (10) and also to the MLEs of Eq. (2). Thus, 1000 discrete probability functions are obtained according to Eqs. (7) and (8). For a specific value $q_{\mathrm{Pm} i}, 1000$ normally distributed values $F_{Q \text { pmi } i}$ are calculated so that for each $q_{\mathrm{Pm} i}$, percentiles $F_{Q \mathrm{pm} i}(\xi)$ and $F_{Q \mathrm{pm} i}(1-\xi)$ corresponding to $\xi$ and $1-\xi$ probabilities are derived. These values are then transformed with Eq. (9) into their corresponding return periods, $T_{\xi}$ and $T_{1-\xi}$, which represent the confidence interval limits for a $\xi$ significance level.

\section{Qualitative sensitivity analysis for peak flows to climate change}

Based on the previously established assumptions, the analysis shows that the following parameters affect the magnitude of the annual maximum peak river flow $q_{\mathrm{Pm}, T}$ :

1. expected number of rainfall events per year, $\beta\left[\mathrm{yr}^{-1}\right]$;

2. shape and scale parameters, $\kappa[-]$ and $\alpha[\mathrm{mm}]$, respectively, of the generalized Pareto distribution for event rainfall depth;

3. storage capacity of the catchment, $S[\mathrm{~mm}]$;

4. initial abstraction of the catchment, $I_{\mathrm{a}}[\mathrm{mm}]$;

5. concentration time of the catchment $t_{\mathrm{C}}[\mathrm{h}]$;

6. SCS peak factor $\lambda_{\mathrm{P}}[-]$;

7. return period, $T$ [year].

Parameters 1 and 2 are directly related to climate input; parameters 3 and 4 are related to the runoff production process in the catchment; parameters 5 and 6 affect the temporal catchment response; finally, parameter 7 is conditioned by the scope of the analysis.

The dependence of $q_{\mathrm{Pm}, T}$ on these eight parameters is dictated by Eqs. (7)-(9). In particular, Eq. (9) dictates the dependence of $q_{\mathrm{Pm}, T}$ on the return period and $\beta$. An increase in the annual number of rainfall events implies an increase in the mean annual rainfall if all other climatic behaviours remain unchanged. Consequently, an increase in $\beta$ does not affect the distribution of flood peaks as long as the events remain distant enough in time and therefore independent, but only affects the number of flood peaks sampled per unit of time. This implies a relevant effect on the flood return period. According to Eq. (9), a $20 \%$ increase in $\beta$ implies a decrease in the flood return period ranging from $0 \%$ (for low $T$ values) to $16.7 \%$ (for high $T$ values). This result is counterintuitive, but one should note that a relevant change in the return period does not necessarily imply a significant change in the flood quantile. As a matter of fact, changes in $q_{\mathrm{Pm}, T}$ can be negligible after a change in $\beta$, especially if the Pareto distribution for event rainfall depth is not strongly skewed. The hypothetical case study presented herein will prove this first conclusion, as shown later. Therefore, it can be concluded that the filtering role of the catchment with regard to changes in $\beta$ is particularly significant when the distribution of event rainfall volume is not strongly skewed.

The sensitivity to the other climatic and catchment parameters is to be analysed through Eq. (7). Specifically, an increase in the flood quantile is induced by an increase in parameters $\alpha$ and $t_{\mathrm{C}}$. The latter is raised to a power less than 1 and therefore is less effective than $\alpha$. Conversely, an increase in $k, S, I_{\mathrm{a}}$ and $\lambda_{\mathrm{P}}$ leads to a decrease in the flood quantile value. These considerations are somewhat intuitive, but 
it is interesting to quantitatively analyse the sensitivity of the flood quantile to production parameters 3 and 4 to quantify the actual filtering role of the catchment on climate variability. The case study is developed with data from Valencia (Spain) presented as a quantitative sensitivity analysis.

\section{Quantitative sensitivity analysis for peak flows to climate variability: a hypothetical case study}

Rainfall model parameters are estimated by maximum likelihood for the 1990-2006 data series in Valencia. Resulting values are $\beta=27.29 \mathrm{yr}^{-1}, \alpha=8.46 \mathrm{~mm}$ and $\kappa=-0.411$. Consequently, the average event depth per event is $\mu_{\mathrm{V}}=14.36 \mathrm{~mm}$ and the coefficient of variation is $\mathrm{CV}_{\mathrm{V}}=2.37$. Further details regarding the rainfall model can be found in Andrés-Doménech et al. (2010). This climate scenario constitutes the reference situation (scenario 0) to perform the sensitivity analysis.

Parameters defining the catchment are adopted in a dimensionless form. This analysis focuses on how the production parameters influence the peak flow statistics. Thus, the storage capacity is considered through the ratio $S / \mu_{\mathrm{V}}$, with an initial abstraction coefficient $k=0.2$ (as in the original version of the SCS-CN model and also mentioned by Ferrer Polo, 1993).

Peak flows are expressed per unit area $\left(\mathrm{mm} \mathrm{h}^{-1}\right)$, so no particular catchment area is assumed.

\subsection{Sensitivity to $\beta$ and to the skewness of the rainfall depth distribution}

The first quantitative analysis performed corresponds to flood quantile sensitivity to $\beta$ and to the skewness of the Pareto distribution governing event rainfall depth. Catchment parameters are set to $S / \mu_{\mathrm{V}}=3.5$ and $t_{\mathrm{C}}=1 \mathrm{~h}$, corresponding to typical values for small catchments in the Valencia region. Concentration time has been set to a representative value, based on a wide hydrological experience in many small catchments of rapid response in the eastern Mediterranean and southeast coast of Spain (Olivares Guillem, 2004; Camarasa Belmonte, 1990). It can be considered a realistic and representative value for a typical ephemeral river in fast-responding small catchments in semi-arid Mediterranean regions.

Relative changes in 10- and 100-year flood quantiles compared to scenario 0 are evaluated for different situations, combining variations in $\beta$ and $\mathrm{CV}_{\mathrm{V}}$. It should be noted that changes in $\beta$ mean that $\mu_{\mathrm{V}}$ should be scaled accordingly. Lowering $\mathrm{CV}_{\mathrm{V}}$ brings the Pareto event rainfall depth distribution close to the exponential distribution (Koutsoyiannis, 2005), while increasing $\mathrm{CV}_{\mathrm{V}}$ progressively increases skewness. Given $\mathrm{CV}_{\mathrm{V}}$ variations, the $\kappa$ parameter of the Pareto distribution, as well as its skewness, vary (Singh and Guo, 1995). Pareto parameters $(\kappa, \alpha)$ for the modified scenarios can be analytically derived from their relationships with $\mathrm{CV}_{\mathrm{V}}$ (Andrés-Doménech et al., 2012).

Figure 1 summarizes the results obtained and shows that changes in $\beta$ do not lead to significant flood quantile variations, unless the distribution of rainfall event depth is highly skewed (higher $\mathrm{CV}_{\mathrm{V}}$ values). As stated in the previous section, the less skewed the rainfall regime is, the less significant the filtering role of the catchment. Conversely, changes in $\mathrm{CV}_{\mathrm{V}}$ are not filtered at all.

\subsection{Sensitivity to the runoff production process}

Catchment production is highly influenced by the balance between rainfall depth and the catchment storage capacity. Thus, sensitivity to the production process should be analysed by introducing variability in rainfall event depth for different $S / \mu_{\mathrm{V}}$ situations.

Arbitrary variations in $v(t)$ statistics from the reference situation (scenario 0) are considered as plausible climate variability scenarios for rainfall event depth. Instead of evaluating the effects of changes on the distribution parameters, changes in the rainfall statistic $\mu_{\mathrm{V}}$ of rainfall event depth are considered. The analysis is now performed by changing $\mu_{\mathrm{V}}$ in the range $\pm 30 \%$ of its reference value (scenarios 1.a, $+30 \%$ and $1 . \mathrm{b},-30 \%$ ). This is in accordance with the maximum expected variability in annual amounts of rainfall for the predicted climate change scenarios in Spain (Brunet et al., 2009). In this scenario $\mathrm{CV}_{\mathrm{V}}$ remains unchanged. It follows that both the $\kappa$ parameter of the Pareto distribution and its skewness also remain unchanged (Singh and Guo, 1995). The modified $\alpha$ values for the modified scenarios can be derived from $\alpha$ dependence on $\mu_{\mathrm{V}}$ (Andrés-Doménech et al., 2012). As stated before, physical parameters defining the catchment are adopted in a dimensionless form. To analyse the filtering role of the catchment depending on production parameters, three realistic storage capacity scenarios are considered, namely, $S / \mu_{\mathrm{V}}=3.5,5$ and 10 .

For each $S / \mu_{\mathrm{V}}$ scenario, Fig. 2 depicts flood quantile variations for scenarios 1.a $\left(+30 \% \mu_{\mathrm{V}}\right)$ and 1.b $(-30 \%$ $\mu_{\mathrm{V}}$ ). Unchanged climatic conditions (scenario 0) yield a flow quantile decrease as $S / \mu_{\mathrm{V}}$ increases. Hence, considering scenario 1.a and 1.b leads to quantile increments associated to $S / \mu_{\mathrm{V}}$ increments. In fact, flood quantile reductions caused by higher $S / \mu_{\mathrm{V}}$ values (scenario 0 ) are more relevant than the variation resulting from $\mu_{\mathrm{V}}$ changes (scenarios 1.a and 1.b).

Another point to be noted is the magnitude of relative variations depending on the return period $T$. For higher return periods, relative changes in flood quantiles tend to be very close to those imposed by the climatic input (mean rainfall event depth $\mu_{\mathrm{V}}$ ). This result reinforces the thesis supported by Gaume (2006) who demonstrated that, for large return periods, the rainfall PDF behaviour is decisive on the catchment response and determines the asymptotic behaviour of the flood peak distribution. On the other hand, for low return 

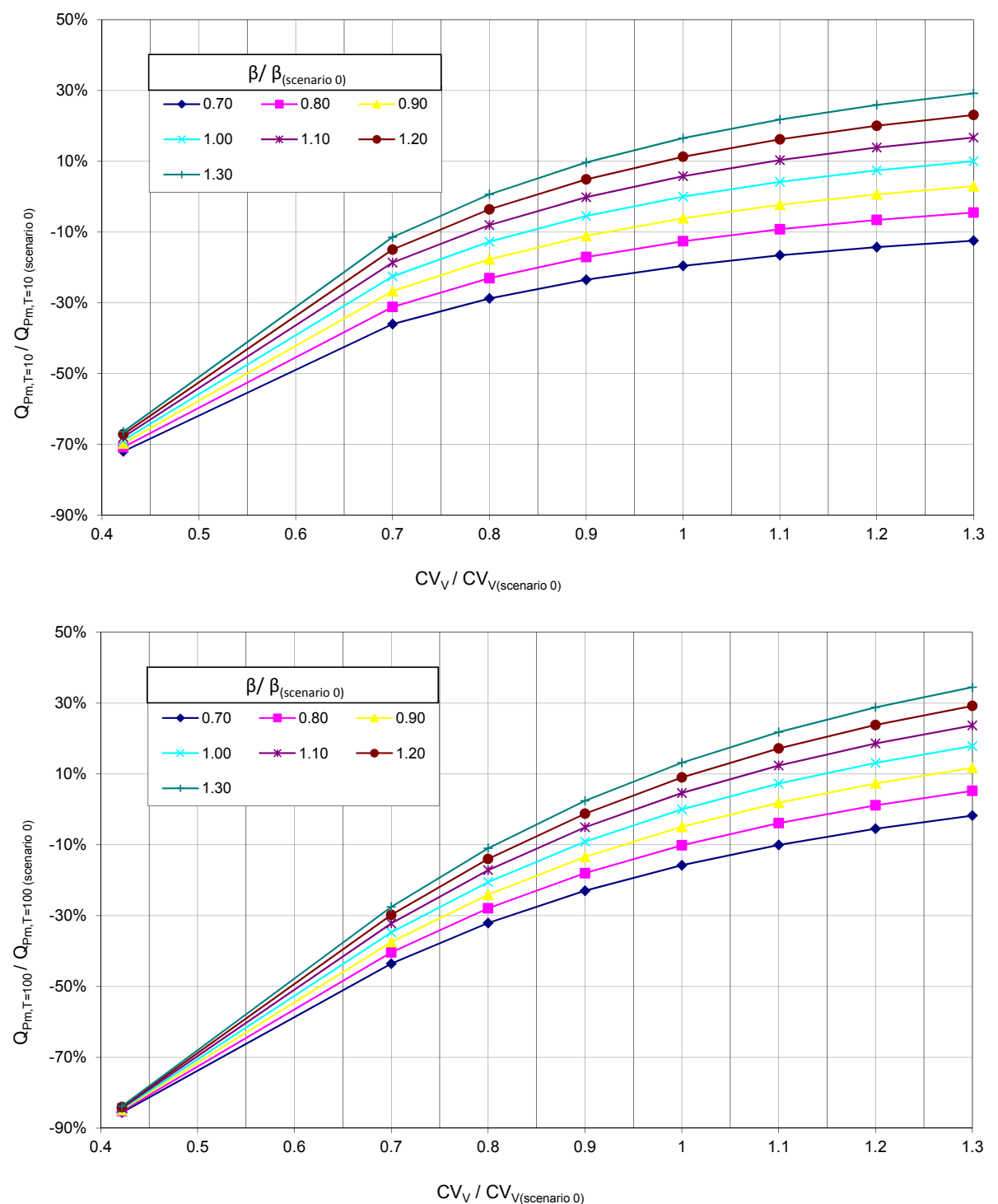

Figure 1. Annual maximum flood quantile variations for changes in $\beta$ and $\mathrm{CV}_{\mathrm{V}}$. Catchment parameters are set to $S / \mu_{\mathrm{V}}=3.5$ and $t_{\mathrm{C}}=1 \mathrm{~h}$. Cases $T=10$ years (top panel) and $T=100$ years (bottom panel).

periods, catchment infiltration parameters strongly influence the derived peak flows for each scenario considered. This result is in accordance with typical Mediterranean catchment behaviour (Gioia et al., 2008; Preti et al., 2011).

\subsection{Peak flow confidence intervals}

Confidence interval limits for a $\xi=0.05$ significance level are obtained for annual maximum peak flow quantiles corresponding to climatic scenario 0 . In order to quantify the statistical significance of peak flow variations after considering various scenarios, eight different climatic scenarios are selected from amongst those previously analysed. These account for climatic variations induced by changes in $\mu_{\mathrm{V}}, \beta$ and $\mathrm{CV}_{\mathrm{V}}$ (Table 1). Annual maximum peak flow quantiles are evaluated for each scenario and variations with regard to scenario 0 are calculated. Figure 3 summarizes the results obtained for each scenario and for the confidence interval limits for scenario 0 . As observed, all results corresponding to $\beta$ and/or $\mathrm{CV}_{\mathrm{V}}$ variations (scenarios 2.a to 4.b) lie within the $90 \%$ confidence interval for scenario 0 . Therefore, results show that there is no concluding evidence from the statistical point of view concerning the significance of peak flow variability induced by these parameters. Nevertheless, when considering peak flow variations due to changes in $\mu_{\mathrm{V}}$ (scenarios 1.a and 1.b), our results confirm the conclusions already drawn in Sect. 3. For low return periods, changes are significant because they are strongly influenced by the runoff production process in the catchment. For larger $T$, the significance of peak flow variations drastically decreases. 


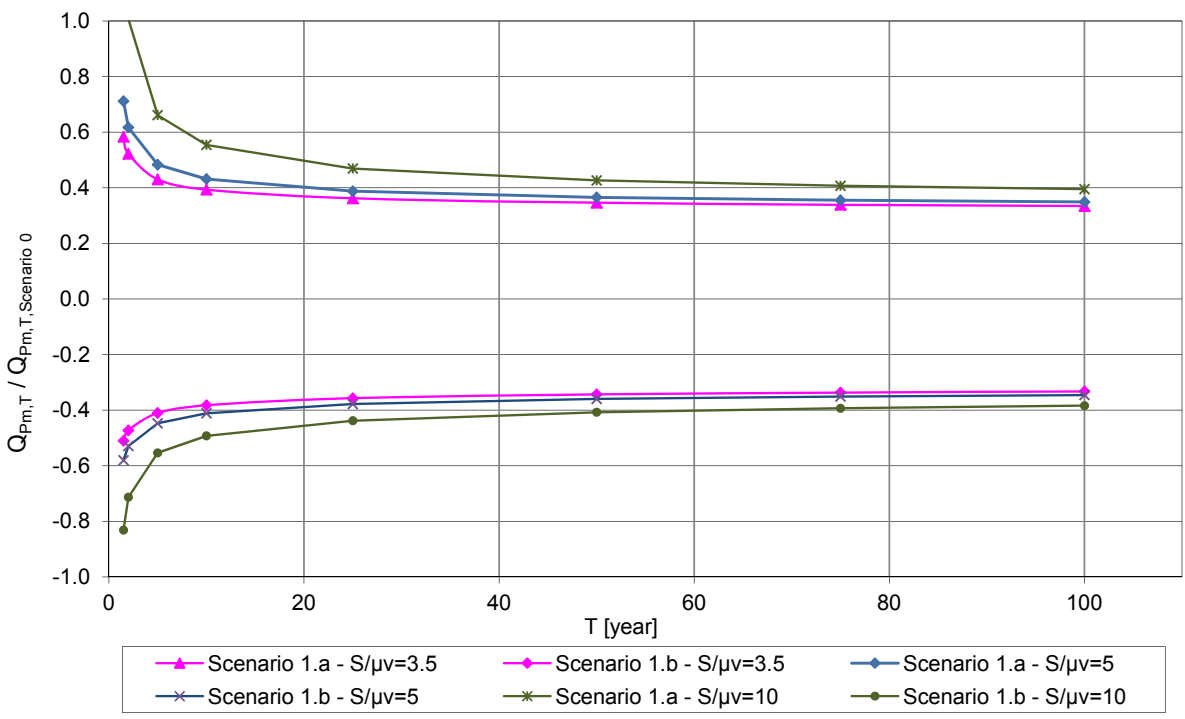

Figure 2. Annual maximum flood quantile variations for scenarios $1 . \mathrm{a}\left(+30 \% \mu_{\mathrm{V}}\right)$ and $1 . \mathrm{b}\left(-30 \% \mu_{\mathrm{V}}\right)$ and for $S / \mu_{\mathrm{V}}=3.5,5$ and 10 .

Table 1. Climate scenarios considered for significance analysis.

\begin{tabular}{|c|c|c|c|c|c|c|c|c|}
\hline $\begin{array}{l}\text { Climatic } \\
\text { scenario }\end{array}$ & $\mu_{\mathrm{V}}$ hypothesis & $\mathrm{CV}_{\mathrm{V}}$ hypothesis & $\beta$ hypothesis & $\begin{array}{c}\mu_{\mathrm{V}} \\
{[\mathrm{mm}]}\end{array}$ & $\mathrm{CV}_{\mathrm{V}}$ & $\begin{array}{r}\alpha \\
{[\mathrm{mm}]}\end{array}$ & $\kappa$ & $\beta$ \\
\hline 0 & Reference scenario & Reference scenario & Reference scenario & 14.36 & 2.37 & 8.46 & 0.411 & 27.29 \\
\hline $1 \mathrm{a}$ & $30 \%$ increase in $\mu_{\mathrm{V}}$ & Reference scenario & Reference scenario & 18.67 & 2.37 & 11.00 & 0.411 & 27.29 \\
\hline $1 b$ & $30 \%$ decrease in $\mu_{\mathrm{V}}$ & Reference scenario & Reference scenario & 10.05 & 2.37 & 5.92 & 0.411 & 27.29 \\
\hline $2 \mathrm{a}$ & Reference scenario & $30 \%$ increase in $\mathrm{CV}_{\mathrm{V}}$ & Reference scenario & 14.36 & 3.08 & 7.94 & 0.447 & 27.29 \\
\hline $2 b$ & Reference scenario & $30 \%$ decrease in $\mathrm{CV}_{\mathrm{V}}$ & Reference scenario & 14.36 & 1.66 & 9.79 & 0.318 & 27.29 \\
\hline $3 a$ & Reference scenario & $30 \%$ increase in $\mathrm{CV}_{\mathrm{V}}$ & $30 \%$ increase in $\beta$ & 14.36 & 3.08 & 7.94 & 0.447 & 35.48 \\
\hline $3 b$ & Reference scenario & $30 \%$ decrease in $\mathrm{CV}_{\mathrm{V}}$ & $30 \%$ increase in $\beta$ & 14.36 & 1.66 & 9.79 & 0.318 & 35.48 \\
\hline $4 a$ & Reference scenario & Reference scenario & $30 \%$ increase in $\beta$ & 14.36 & 2.37 & 8.46 & 0.411 & 35.48 \\
\hline $4 \mathrm{~b}$ & Reference scenario & Reference scenario & $30 \%$ decrease in $\beta$ & 14.36 & 2.37 & 8.46 & 0.411 & 19.11 \\
\hline
\end{tabular}

\section{Conclusions}

The research presented herein highlights the filtering role brought on by catchment processes through a simple rainfallrunoff transfer function. The peak flow distribution is analytically derived from a rainfall model using the CN-SCS hydrological conceptualization. Variability of annual maximum peak flows is quantitatively analysed when changes in climatic input are introduced.

Such a modelling approach involves certain limitations, and yet it benefits from the analytical simplicity and practical applicability. Consequently, numerical results obtained after simulations cannot be transferred to hydrological regimes that differ from the type of Mediterranean catchments specified here. Nevertheless, the proposed methodology represents a useful modelling framework for further studies, and may constitute a first step forward towards a more complex analysis after relaxing some of the initial assumptions.
Although certain dominant drivers of the hydrological response, like variability of watershed properties or land use changes, have not been explicitly considered in this study, the proposed modelling framework has the potential to incorporate those drivers to a certain extent, and thus, allow for the effect of such variability to be assessed and compared in future studies.

The results obtained from the sensitivity analysis can be summarized as follows:

1. The filtering role of the catchment with regard to changes in the annual number of rainfall events is particularly significant when the rainfall event volume distribution is not strongly skewed.

2. Sensitivity to the runoff production parameters in the catchment is highly influenced by the balance between rainfall depth and catchment storage capacity. For higher return periods, relative changes in annual maxi- 


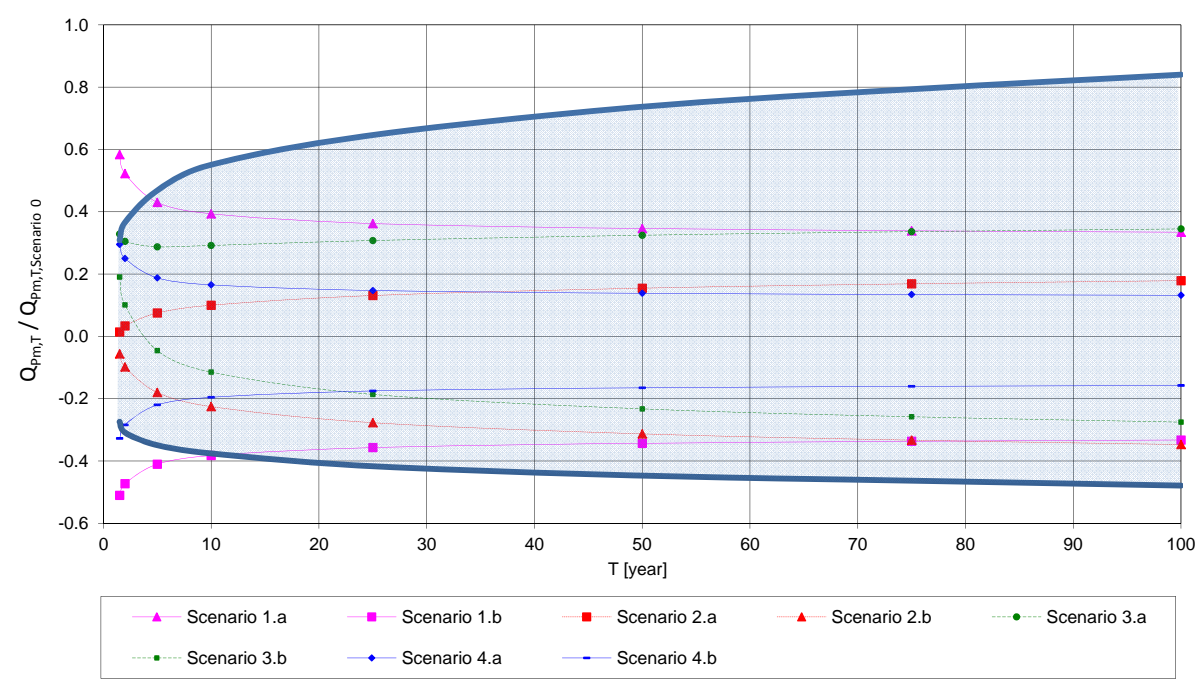

Figure 3. Annual maximum flood quantile variations for scenarios defined in Table 1 and $\xi=0.05$ confidence interval for scenario 0 peak flow distribution (shaded area). Catchment parameters are set to $S / \mu_{\mathrm{V}}=3.5$ and $t_{\mathrm{C}}=1 \mathrm{~h}$.

mum flood quantiles tend to be asymptotically similar to those imposed by the climatic input. For low return periods, the infiltration process strongly influences the derived peak flow distribution, which is in accordance with typical Mediterranean catchment hydrological behaviour.

3. In the range of low return periods (1 to 10 years), the only parameter of the rainfall model which actually affects significantly peak flows is the mean rainfall event depth. The other parameters involved in the rainfall modelling approach play a negligible role in this case, mainly due to the threshold-based conceptualization used in the CN-SCS model.

Although these conclusions were derived under simplified assumptions, results correspond to a rigorous sensitivity analysis performed for realistic hydrological conditions of typical ephemeral, fast-responding rivers, and thus provide indications of general validity for small Mediterranean catchments responding under these simple rainfall-runoff models. Further research should focus on the limitations of such a simple model for high and very high return periods and on the dependence of peak flow variability on time-dependent parameters of the rainfall-runoff transformation. On the other hand, the research could be extended by including in the rainfall-runoff deterministic model additional climatic perturbations and land use changes, as well as by exploring possible parameter interaction effects.

Acknowledgements. The authors wish to thank Debra Westall for revising the paper. The present work was (partially) developed within the framework of the Panta Rhei Research Initiative of the International Association of Hydrological Sciences (IAHS).
Edited by: S. Attinger

\section{References}

Allamano, P., Claps, P., and Laio, F.: Global warming increases flood risk in mountainous areas, Geophys. Res. Lett., 36, L24404, doi:10.1029/2009GL041395, 2009.

Andrés-Doménech, I., Montanari, A., and Marco, J. B.: Stochastic rainfall analysis for storm tank performance evaluation, Hydrol. Earth Syst. Sci., 14, 1221-1232, doi:10.5194/hess-14-12212010, 2010.

Andrés-Doménech, I., Montanari, A., and Marco, J. B.: Efficiency of Storm Detention Tanks for Urban Drainage Systems under Climate Variability, J. Water Resour. Pl. Manage., 138, 36-46, doi:10.1061/(ASCE)WR.1943-5452.0000144, 2012.

Bloeschl, G. and Montanari, A.: Climate change impacts - throwing the dice?, Hydrol. Process., 24, 374-381, doi:10.1002/hyp.7574, 2010.

Botter, G., Basso, S., Rodriguez-Iturbe, I., and Rinaldo, A.: Resilience of river flow regimes, P. Natl. Acad. Sci. USA, 110, 12925-12930, doi:10.1073/pnas.1311920110, 2013.

Brunet, M., Casado, M. J., de Castro, M., Galán, P., López, J. A., Martín, J. M., Pastor, A., Petisco, E., Ramos, P., Ribalaygua, J., Rodríguez, E., Sanz, I., and Torres, L.: Generación de escenarios regionalizados de cambio climático para España, Agencia Estatal de Meteorología (AEMET), Ministerio de Medio Ambiente y Medio Rural y Marino, Madrid, 2009.

Camarasa Belmonte, A. M.: Génesis de avenidas en pequeñas cuencas semiáridas: la Rambla de Poyo (Valencia), Cuad. De Geogr., 48, 81-104, 1990.

De Zea Bermudez, P. and Kotz, S.: Parameter estimation of the generalized Pareto distribution - Part I, J. Stat. Plan. Infer., 140-6, 1353-1373, doi:10.1016/j.jspi.2008.11.019, 2010.

Di Baldassarre, G., Montanari, A., Lins, H., Koutsoyiannis, D., Brandimarte, L., and Blöschl, G.: Flood fatalities in Africa: 
From diagnosis to mitigation, Geophys. Res. Lett., 37, L22402, doi:10.1029/2010GL045467, 2010.

Eagleson, P. S.: Dynamics of flood frequency, Water Resour. Res., 8, 878-898, doi:10.1029/WR008i004p00878, 1972.

Ferrer Polo, J.: Recomendaciones para el cálculo hidrometeorológico de avenidas, Centro de Estudios y Experimentación de Obras Públicas, Madrid, 1993.

Gaume, E.: On the asymptotic behavior of flood peak distributions, Hydrol. Earth Syst. Sci., 10, 233-243, doi:10.5194/hess-10-2332006, 2006.

Gioia, A., Iacobellis, V., Manfreda, S., and Fiorentino, M.: Runoff thresholds in derived flood frequency distributions, Hydrol. Earth Syst. Sci., 12, 1295-1307, doi:10.5194/hess-12-12952008, 2008.

Haberlandt, U. and Radtke, I.: Hydrological model calibration for derived flood frequency analysis using stochastic rainfall and probability distributions of peak flows, Hydrol. Earth Syst. Sci., 18, 353-365, doi:10.5194/hess-18-353-2014, 2014.

Kay, A. L., Jones, R. G., and Reynard, N. S.: RCM rainfall for UK flood frequency estimation, II. Climate change results, J. Hydrol., 318, 163-172, doi:10.1016/j.jhydrol.2005.06.013, 2006.

Koutsoyiannis, D.: Uncertainty, entropy, scaling and hydrological stochastics, 1. Marginal distributional properties of hydrological processes and state scaling, Hydrolog. Sci. J., 50, 381-404, doi:10.1623/hysj.50.3.381.65031, 2005.

Koutsoyiannis, D. and Montanari, A.: Negligent killing of scientific concepts: the stationarity case, Hydrolog. Sci. J., doi:10.1080/02626667.2014.959959, in press, 2014.

Koutsoyiannis, D., Montanari, A., Lins, H. F., and Cohn, T. A.: Discussion of "The implications of projected climate change for freshwater resources and their management". Climate, hydrology and freshwater: towards an interactive incorporation of hydrological experience into climate research, Hydrolog. Sci. J., 54, 394-405, doi:10.1623/hysj.54.2.394, 2009.

Kundzewicz, Z. W., Mata, L. J., Arnell, N. W., Döll, P., Kabat, P., Jiménez, B., Miller, K. A., Oki, T., Sen, Z., and Shiklomanov, I. A.: Freshwater resources and their management, Climate Change 2007: Impacts, Adaptation and Vulnerability, in: Contribution of Working Group II to the Fourth Assessment Report of the Intergovernmental Panel on Climate Change, edited by: Parry, M. L., Canziani, O. F., Palutikof, J. P., van der Linden, P. J., and Hanson, C. E., Cambridge University Press, Cambridge, UK, 173-210, 2007.

Kundzewicz, Z. W., Mata, L. J., Arnell, N. W., Döll, P., Jimenez, B., Miller, K., Oki, T., Sen, Z., and Shiklomanov, I.: The implications of projected climate change for freshwater resources and their management, Hydrolog. Sci. J., 53, 3-10, doi:10.1623/hysj.53.1.3, 2008.

Madsen, H. and Rosbjerg, D.: The partial duration series method in regional index-flood modeling, Water Resour. Res., 33, 737-746, doi:10.1029/96WR03847, 1997.
Madsen, H., Rasmussen, P. F., and Rosbjerg, D.: Comparison of annual maximum series and partial duration series for modeling extreme hydrologic events, 1. At-site modeling, Water Resour. Res., 33, 747-757, doi:10.1029/96WR03848, 1997.

Milly, P. C. D., Wetherald, R. T., Dunne1, K. A., and Delworth, T. L.: Increasing risk of great floods in a changing climate, Nature, 415, 514-517, doi:10.1038/415514a, 2002.

Montanari, A. and Koutsoyiannis, D.: Modeling and mitigating natural hazards: Stationarity is immortal!, Water Resour. Res., 50, 9748-9756, doi:10.1002/2014WR016092, 2014.

Olivares Guillem, A.: Modelación hidrológica pseudo-distribuida del barranco del Carraixet: aplicación al episodio de octubre de 2000, Cuad. De Geogr., 76, 155-182, 2004.

Papa, F. and Adams, B. J.: Application of derived probability and dynamic programming techniques to planning regional stormwater management systems, Water Sci. Technol., 36, 227-234, 1997.

Preti, F., Forzieri, G., and Chirico, G. B.: Forest cover influence on regional flood frequency assessment in Mediterranean catchments, Hydrol. Earth Syst. Sci., 15, 3077-3090, doi:10.5194/hess-15-3077-2011, 2011.

Sangati, M., Borga, M., Rabuffetti, D., and Bechini, R.: Influence of rainfall and soil properties spatial aggregation on extreme flash flood response modelling: An evaluation based on the Sesia river basin, North Western Italy, Adv. Water Resour., 32, 1090-1106, 2009.

SCS: National Engineering Handbook, Section 4: Hydrology, Soil Conservation Service, USDA, Washington, D.C., 1971.

Singh, V. P. and Guo, H.: Parameter estimation for 3-parameter generalized Pareto distribution by the principle of maximum entropy (POME), Hydrolog. Sci. J., 40, 165-181, doi:10.1080/02626669509491402, 1995.

Smith, R. L.: Threshold methods for sample extremes, in: Statistical Extremes and Applications, edited by: de Oliveira, J. T., Reidel, Dordrecht, 621-638, 1984.

Soulis, K. X. and Valiantzas, J. D.: SCS-CN parameter determination using rainfall-runoff data in heterogeneous watersheds - the two-CN system approach, Hydrol. Earth Syst. Sci., 16, 10011015, doi:10.5194/hess-16-1001-2012, 2012.

Troch, P. A., Carrillo, G., Sivapalan, M., Wagener, T., and Sawicz, K.: Climate-vegetation-soil interactions and long-term hydrologic partitioning: signatures of catchment co-evolution, Hydrol. Earth Syst. Sci., 17, 2209-2217, doi:10.5194/hess-17-22092013, 2013.

Tzavelas, G., Paliatsos, A. G., and Nastos, P. T.: Brief communication "Models for the exceedances of high thresholds over the precipitation daily totals in Athens, Greece", Nat. Hazards Earth Syst. Sci., 10, 105-108, doi:10.5194/nhess-10-105-2010, 2010.

Viglione, A. and Blöschl, G.: On the role of storm duration in the mapping of rainfall to flood return periods, Hydrol. Earth Syst. Sci., 13, 205-216, doi:10.5194/hess-13-205-2009, 2009. 